\title{
Iron-deficiency Anemia and Chronic Kidney Disease: An Overview
}

\author{
Richa Saxena ${ }^{1}$, Garima Sharma², Nikhita Gulati ${ }^{3}$
}

\begin{abstract}
Anemia is known to be a common and clinically important cause of chronic kidney disease (CKD). With progression of CKD, various factors can be attributed to reduction in hemoglobin $(\mathrm{Hb})$ levels. However, reduced production of erythropoietin (EPO) due to impaired functioning of kidneys remains the central cause. The most effective treatment of anemia associated with CKD involves iron replacement and erythropoieticstimulating agents (ESAs). Diagnosis of iron-deficiency anemia (IDA) in CKD patients is complicated due to the relatively poor predictive ability of routine serum iron indices such as ferritin and transferrin saturation. Invasive methods such as bone marrow iron stores or erythropoietic response to supplemental iron for detection of iron deficiency serve as the gold standard and are required for confirmation of diagnosis.

Keywords: Anemia, Chronic kidney disease, Hemoglobin, Hepcidin, Iron deficiency, Iron loss.

World Journal of Anemia (2018): 10.5005/jp-journals-10065-0037
\end{abstract}

\section{INTRODUCTION}

Iron-deficiency anemia is a common complication of chronic kidney disease (CKD). ${ }^{1}$ Per records in 2010, the worldwide prevalence rate of anemia was estimated at $33 \%$, with iron deficiency being the leading cause in half of these cases. In patients with CKD, anemia is a clinically significant burden and it becomes more prevalent with declining glomerular filtration rate (GFR). Anemia is associated with reduced quality of life (QoL) and increased cardiovascular (CV) morbidity and mortality. ${ }^{2}$

Chronic kidney disease can lead to either absolute or functional iron deficiency. In functional iron deficiency, while the total body stores are adequate, slow release of iron from store into circulation is insufficient to compensate the loss due to increased rate of erythropoiesis driven by erythropoietic-stimulating agents (ESAs). ${ }^{3-5}$

The World Health Organization (WHO) defines anemia as hemoglobin $(\mathrm{Hb})$ level $<12 \mathrm{~g} / \mathrm{dL}$ in women and $<13 \mathrm{~g} / \mathrm{dL}$ in men (13.2 $\mathrm{g} / \mathrm{dL}$ in men $>70$ years). ${ }^{6}$ The potential CKD patients with estimated GFR (eGFR) $<60 \mathrm{~mL} /$ minute $/ 1.73 \mathrm{~m}^{2}$ should also be screened for anemia during initial evaluation. ${ }^{2}$

Life expectancy from kidney failure is shorter than most common cancers, ${ }^{7,8}$ and most hospital admissions and deaths in CKD patients are due to CV causes., ${ }^{9,10}$

\section{Causes of Iron-deficiency Anemia}

When kidneys fail to function, the amount of erythropoietin (EPO) produced is significantly reduced. This, in turn, reduces the number of red blood cells produced by the bone marrow that leads to the development of anemia. Therefore, blood which has a few red blood cells deprives oxygen required by the body (Fig. 1).

Apart from the reduced production of RBCs, some of the major causes of iron-deficiency anemia (IDA) in CKD include blood loss due to blood retention in tubes and apparatus during hemodialysis, malnutrition or low levels of nutrients in food, inflammatory problems such as lupus, arthritis, or inflammatory bowel disease, diabetic ulcers, or problems associated with bone marrow (Figs 2 and 3). ${ }^{12}$

\begin{abstract}
'Jaypee Brothers Medical Publishers, New Delhi, India
${ }^{2}$ Department of Pharmaceutics, Jamia Hamdard (a Deemed to be University), New Delhi, India

${ }^{3}$ Amity Institute of Biotechnology, Amity University, Noida, Uttar Pradesh, India

Corresponding Author: Richa Saxena, Jaypee Brothers Medical Publishers, New Delhi, India, Phone: +91 9971234834, e-mail: synapse94@hotmail. com

How to cite this article: Saxena R, Sharma G, Gulati N. Iron-deficiency Anemia and Chronic Kidney Disease: An Overview. World J Anemia 2018;2(3-4):85-89.
\end{abstract}

Source of support: Nil

Conflict of interest: None

\section{Signs And Symptoms}

Fatigue, paleness, weakness, dizziness, headaches, chest pain, and shortness of breath are the various symptoms of iron deficiency in CKD patients. ${ }^{13}$

\section{Metabolism of Iron in Chronic Kidney Disease}

Iron is a requisite for the synthesis of $\mathrm{Hb}$ which further aids in transporting oxygen to various tissues across the body. Additionally, heme- and nonheme iron are elementary components of enzymes in the mitochondrial chain which utilizes oxygen in energy production. Therefore, iron is indispensable for transporting and storing oxygen and for energy metabolism. ${ }^{14}$

Iron has the ability to recycle within the body as the red blood cells are phagocytosed by reticuloendothelial macrophage and the content of iron is either taken up for hematopoiesis in case it is required or stored up for later use.

Hepcidin is a main factor responsible for regulation of iron metabolism. It is a small peptide hormone which is further synthesized and secreted by liver ${ }^{15}$ and prevents the transport of iron by binding to ferroportin located on the basal membrane of enterocytes, reticuloendothelial cells, and hepatocytes. The binding of hepcidin leads to internalization of ferroportin from

(c) The Author(s). 2018Open Access This article is distributed under the terms of the Creative Commons Attribution 4.0 International License (https://creativecommons. org/licenses/by-nc/4.0/), which permits unrestricted use, distribution, and non-commercial reproduction in any medium, provided you give appropriate credit to the original author(s) and the source, provide a link to the Creative Commons license, and indicate if changes were made. The Creative Commons Public Domain Dedication waiver (http://creativecommons.org/publicdomain/zero/1.0/) applies to the data made available in this article, unless otherwise stated. 


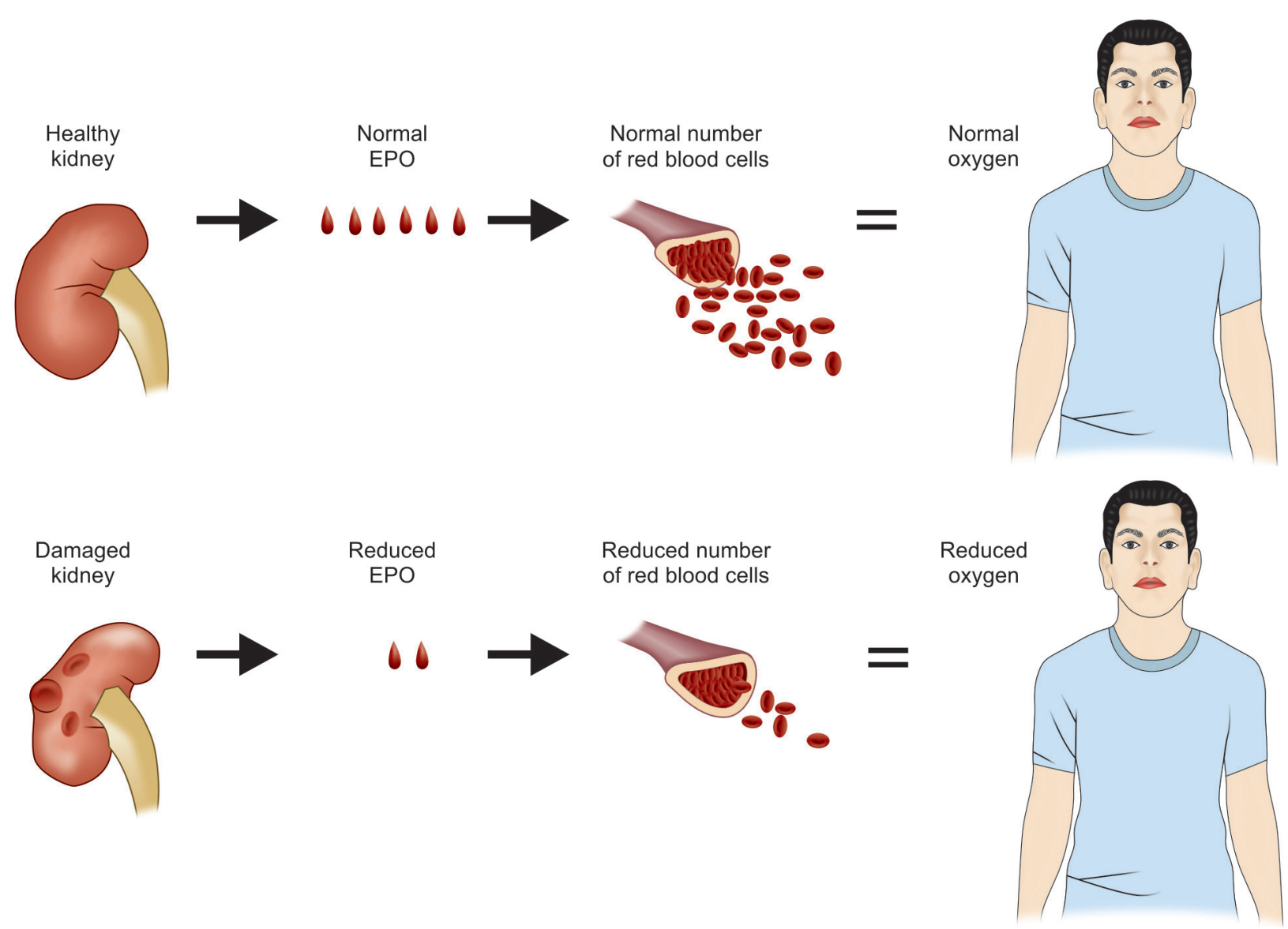

Fig. 1: Effects of damaged kidney on anemia. Source: NIH: Department of Health and Human Services. (2014). Anemia in Chronic Kidney Disease [online]. Available from http://www.pkdiet.com/pdf/anemia_508.pdf [Last accessed December, 2019] ${ }^{11}$

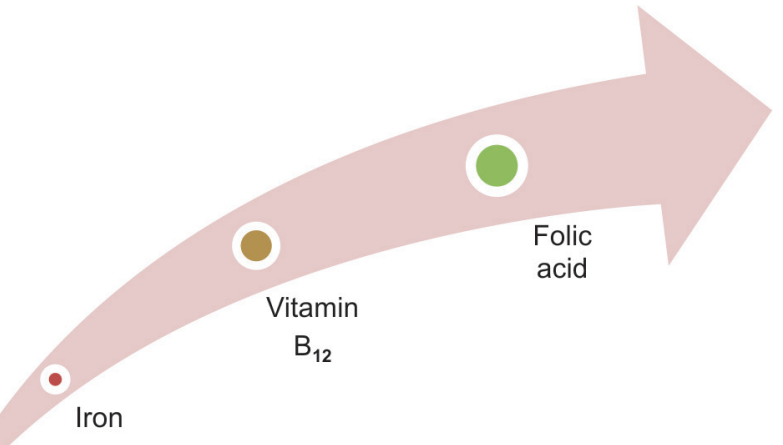

Fig. 2: Types of nutrients present in food

plasma membrane into the cell and further causes degradation. ${ }^{16}$ Various physiology stimuli such as iron stores, hypoxia, inflammation, and erythropoiesis alone or in combination regulate the hepcidin levels in the body. ${ }^{17-21}$

However, hepcidin levels are raised in CKD patients and negatively correlated with GFR. ${ }^{4,22}$ The factors responsible for CKD include increased inflammatory cytokines, reduced renal clearance, and reduced EPO levels. ${ }^{5-23}$

In CKD patients, absolute iron deficiency arise from an increased rate of blood loss during dialysis. ${ }^{24}$ Iron loss is contributed by frequent phlebotomies and blood remaining in the dialysis tubing. ${ }^{25}$

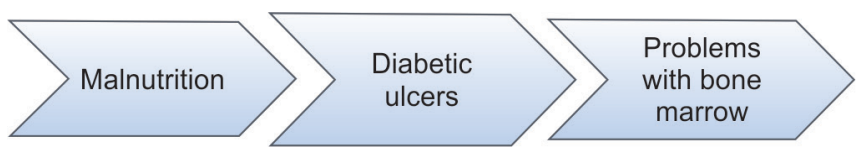

Fig. 3: Some of the major causes of iron-deficiency anemia in chronic kidney disease (CKD)

The rate of iron loss is getting high per year, i.e., 1 to $3 \mathrm{~g} /$ year due to gastrointestinal bleeding from the combination of gastritis and platelet dysfunction. This phenomenon is common in dialysis- and nondialysis-dependent CKD patients. ${ }^{26}$

\section{Various Outcomes of Iron Deficiency in Chronic Kidney Disease}

Anemia is associated with reduced QoL and increased CV morbidity and mortality. ${ }^{2}$ A study was conducted in which 27,998 patients with CKD were enrolled. The follow-up was done for almost 5.5 years. The prevalence rate of anemia, congestive heart failure, coronary artery disease, and type 2 diabetes mellitus was higher in patients who died compared to those who survived, despite shorter observation period. ${ }^{27-30}$ It was stated that patients who died because of increased rates of heart disease and anemia suggested that anemia increases the progression of heart disease and risk of death. ${ }^{27}$

A cohort study was conducted among 5,885 patients with CKD in whom the $\mathrm{Hb}$ levels were measured. ${ }^{31}$ Anemia is known to be a predictor of excess CV hospitalizations, excess mortality, and excess end-stage renal disease (ESRD). Patients with the most 
severe anemia levels $<10.5 \mathrm{~g} / \mathrm{dL}$, with an increased rate of mortality with hazard ratio (HR): 5.27, 95\% confidence interval (CI): 4.37-6.35; CV hospitalizations with HR: $2.18,95 \% \mathrm{Cl}$ : 1.76-2.70; and ESRD with HR: $5.46,95 \%$ Cl: $3.38-8.82$ when compared to those who were not anemic.

In a prospective study on 853 CKD stage $3-5$, predialysis patients reported an association between mortality rates and severity of anemia. ${ }^{28}$ Over the period of 2 years, the $\mathrm{Hb}$ values were longitudinally collected over a median follow-up of about 2 years. A time-averaged $\mathrm{Hb}$ with $<11 \mathrm{~g} / \mathrm{dL}$ was associated with increased mortality, compared to the group with a time-averaged $\mathrm{Hb}$ of $>13 \mathrm{~g} / \mathrm{dL} .{ }^{21}$ Even those with a time-averaged $\mathrm{Hb}$ of $11-12 \mathrm{~g} / \mathrm{dL}$ had a significantly higher $\mathrm{HR}$ for mortality (HR: $1.8 ; 95 \% \mathrm{Cl}: 1.23-2.63)$ compared to the group with a time-averaged $\mathrm{Hb}$ of $>13 \mathrm{~g} / \mathrm{dL}$. Lower time-averaged $\mathrm{Hb}$ levels also correlated with a statistically significant increased risk in the composite end point of predialysis mortality and ESRD as follows: HR: 2.57 (95\% Cl: 1.85-3.58) for $\mathrm{Hb}<11 \mathrm{~g} / \mathrm{dL}, \mathrm{HR}: 1.97$ (95\% Cl: 1.45-2.66) for $\mathrm{Hb}<12 \mathrm{~g} / \mathrm{dL}$, again, compared with $\mathrm{Hb}>13 \mathrm{~g} / \mathrm{dL}^{32}$ Anemia in CKD may be frequently associated with a reduced QoL. In a study that examined the relationship between kidney disease quality of life (KDQofL) questionnaire domains and $\mathrm{Hb}$ levels in 1,200 patients with stages 3,4 , and 5 of CKD, higher $\mathrm{Hb}$ levels were associated with improved QoL domains of the KDQofL questionnaire. The most dramatic improvements in the various QoL domains occurred between the groups with $\mathrm{Hb}<11 \mathrm{~g} / \mathrm{dL}$ and $\mathrm{Hb}$ of $11-12 \mathrm{~g} / \mathrm{dL}^{32}$

\section{Diagnosis of Iron Deficiency in CKD Patients}

For diagnosis of IDA, various parameters such as serum iron, ferritin, total iron-binding capacity, and transferrin saturation (TSAT = plasma iron divided by the total iron-binding capacity $\times 100$ ). Absolute IDA in CKD leads to depletion of iron reserves and TSAT values drop to $\leq 20 \%$, and serum ferritin is $<100 \mathrm{ng} / \mathrm{m}$ in predialysis and peritoneal dialysis (PD) patients or $\leq 200 \mathrm{ng} / \mathrm{mL}$ among patients undergoing hemodialysis. In functional IDA, despite sufficient iron

Table 1: Normal reference range

\begin{tabular}{ll}
\hline Parameter & Normal reference range \\
\hline $\mathrm{Hb}$ & $11.0-12.0 \mathrm{~g} / \mathrm{dL}$ \\
$\mathrm{Fe}$ & $>30 \mu \mathrm{g} / \mathrm{dL}$ \\
$\mathrm{TIBC}$ & $<400 \mu \mathrm{g} / \mathrm{dL}$ \\
TSAT & $\geq 20 \%$ \\
Ferritin & $100-799 \mathrm{ng} / \mathrm{mL}(\mathrm{NDD}) ; 200-799 \mathrm{ng} / \mathrm{mL}(\mathrm{HDD})$ \\
\hline
\end{tabular}

$\mathrm{Fe}$, ferritin; $\mathrm{Hb}$, hemoglobin; $\mathrm{HDD}$, hemodialysis dependent; NDD, nondialysis dependent; TIBC, total iron-binding capacity; TSAT, transferrin saturation reserves, deficiency occurs due to inadequate mobilization and inability to keep up with RBC production during erythropoiesis driven by ESA therapy which leads to TSAT $<20 \%$ with significantly elevated ferritin (i.e., as high as $800 \mathrm{ng} / \mathrm{mL}$ ). ${ }^{33-36}$ In such conditions, the body fails to reach the target $\mathrm{HB}$ levels despite high doses of ESA.

Reference range of various parameters essential for diagnosis of IDA is given in Table 1.

National Institute for Health and Care Excellence guidelines (2015) suggest the measurement of hypochromic red blood cells (HRCs) percentage and reticulocyte $\mathrm{Hb}$ content $(\mathrm{CHr})$ to determine whether the $\mathrm{Hb}$ content of RBCs is a better predictor of functional iron deficiency, iron availability for $\mathrm{Hb}$ synthesis, and responsiveness to iron supplementation as compared to TSAT and ferritin. Although the cutoff $\mathrm{CHr}<29 \mathrm{pg}$ and $\mathrm{HRC}>6 \%$ are used to diagnose iron deficiency, neither the percentage of $\mathrm{HRC}$ nor the $\mathrm{CHr}$ can be used to differentiate between absolute and functional iron deficiency. ${ }^{37}$

Kidney Disease Improving Global Outcomes (KDIGO) guidelines recommend anemia screening only when clinical symptoms are present. In CKD stage 3, annual testing is recommended, CKD stage 4-5 twice per year, and every 3 months in dialysis patients in CKD-5 stage. In iron-deficient CKD patients not undergoing any ESA, the $\mathrm{Hb}$ concentration should be screened once in every 3 months in CKD stage 3-5 (nondialytic patients) and CKD stage 5 (PD) and monthly in CKD stage 5 hemodialysis. ${ }^{38}$

\section{Treatment and Management of IDA}

According to KDIGO guidelines, ${ }^{38}$ the course of treatment for IDA in CKD patients with TSAT is $\leq 30 \%$ and ferritin is $\leq 500 \mathrm{ng} / \mathrm{mL}$ is summarized in Table 2.

\section{Nonhemodialysis in CKD Patients}

The primary step in the management of iron deficiency is improving iron and $\mathrm{Hb}$ levels. Iron can be administered either orally or intravenously (IV). While oral iron supplementation is a preferred mode of treatment due to its cost-effectiveness and ease of use, IV administration is preferred in severe anemia case when administration of larger doses of iron is required to rapidly obtain optimal Hb levels. ${ }^{35,39-41}$

Literature suggests that IV iron supplementation has greater efficacy over iron supplementation. In a 2008 meta-analysis of randomized controlled trial (RCT) by Rozen-Zvi et al., the effect of IV and oral iron supplementation were evaluated in anemic CKD patients and it was concluded that CKD patients on hemodialysis therapy have better $\mathrm{Hb}$ level response when treated with IV iron. ${ }^{42}$ Avni et al. evaluated the efficacy and safe of oral, intramuscular, and IV iron and reported that IV iron therapy has comparable safety profile to oral iron, had fewer gastrointestinal side effects, and was not associated with increased risk of severe adverse events or infections. ${ }^{43}$ A systemic review and meta-analysis by Shepshelovich

Table 2: Course of treatment

\begin{tabular}{|c|c|c|c|}
\hline Patients & Therapy type & Dialysis status & Treatment \\
\hline \multirow{4}{*}{ CKD + IDA } & Neither iron supplementation nor ESA therapy & Dialysis & IV iron supplementation \\
\hline & & Nondialysis & $\begin{array}{l}1-3 \text { months oral iron } \\
\text { supplementation }\end{array}$ \\
\hline & ESA therapy but not iron supplementation & Dialysis & IV iron supplementation \\
\hline & & Nondialysis & $\begin{array}{l}1-3 \text { months oral iron } \\
\text { supplementation }\end{array}$ \\
\hline
\end{tabular}

CKD, chronic kidney disease; ESA, erythropoiesis-stimulating agent; IDA, iron-deficiency anemia; IV, intravenous 
et al. also recommends IV iron replacement for patients with CKD stage 5D and support the use of IV iron over oral supplementation for patients with CKD stages 3-5. ${ }^{44}$ Similar findings were reported by Sargent et al. who assessed the safety and effectiveness of IV iron supplementation in CKD stage 5 patients who have not yet received dialysis (CKD 5 ND). According to this prospective cohort study, iron supplementation is associated with $15 \%$ lower risk of death among CKD 5 ND patients who received ESA treatment. ${ }^{45}$

Based on these studies, it can be concluded that the benefits of IV iron supplementation is the preferred route of administration in ND-CKD.

Over the years, ESA therapy has become the choice of treatment for the management of anemia in CKD. The ESAs not only reduce the symptoms of anemia but also improve QoL, increase survival rates, reduce the number of transfusions required, and decrease the progression of renal failure. ${ }^{46,47}$ However, various factors such as etiology of anemia, target $\mathrm{Hb}$, route of administration, and presence of hypertension should be considered before prescribing ESAs. ${ }^{48}$ In contrast to the available data, some studies report the association between administration of high doses of ESA and increased mortality rates and high incidence of development of thrombotic and cerebrovascular complications. ${ }^{49}$ Thus, the potential risk of ESA treatment in anemia management remains debatable.

\section{Chronic Kidney Disease Patients on Dialysis}

Chronic kidney disease patients with a history of dialysis or who are currently on dialysis are at high risk of developing IDA due to iron loss from blood retention in the dialysis machine and tubes. ${ }^{45-50}$ The first-line treatment of choice is repeated loading dose of $1,000 \mathrm{mg}$ of iron administered via IV until the $\mathrm{Hb}$ level rises, followed by maintenance phase with regular small doses of iron.

Numerous studies on CKD patients undergoing hemodialysis report the effectiveness of IV iron supplementation in correcting $\mathrm{Hb}$ levels as compared to oral iron supplementation, regardless of ESA treatment. ${ }^{38,42}$ Similar findings were reported by Locatelli et al., where IV iron treatment had better response time as opposed to oral supplementation recommended by KDIGO and European Renal Best Practice (ERBP) guidelines. ${ }^{35,44}$ Another study by Coyne et al. reported the association of elevated ferritin levels and increased mortality. ${ }^{51}$ However, dialysis patients' response to IV iron with elevated ferritin (DRIVE) trial did not show any such results. ${ }^{51} \mathrm{~A}$ prospective RCT by Macdougall et al. showed that a high-dose proactively administered IV iron regimen on patients undergoing hemodialysis was much more effective than a low-dose regimen administered reactively, and it significantly reduced the risk of death and nonfatal CV events. The high-dose strategy also lowered the dose of ESA, number of blood transfusions and hospitalizations. ${ }^{52}$

\section{Conclusion}

Iron-deficiency anemia is the most common form of anemia and an associated complication of CKD. The CKD patients can develop either absolute or functional iron deficiency. Absolute iron deficiency is defined by severely reduced or absent iron stores, leading to $\leq 20 \%$ TSAT levels and $\leq 200 \mathrm{ng} / \mathrm{mL}$ serum ferritin levels in hemodialysis-dependent CKD patients and $\leq 100 \mathrm{ng} / \mathrm{mL}$ in predialysis CKD patients. Functional iron deficiency is defined by adequate iron stores but insufficient iron availability for incorporation into erythroid precursors. Oral iron supplementation is the preferred form of treatment due to the ease of use and costeffectiveness. In severe cases, ESA therapy is preferred to readily relief symptoms of anemia and reduce the number of transfusions required.

\section{References}

1. Gafter-Gvili A, Schechter A, Rozen-Zvi B. Iron deficiency anemia in chronic kidney disease. Acta Haematol 2019;142(1):44-50. DOI: $10.1159 / 000496492$.

2. Aoun M, Karam R, Sleilaty G, et al. Iron deficiency across chronic kidney disease stages: Is there a reverse gender pattern? PLoS One 2018;13(1):e0191541. DOI: 10.1371/journal.pone.0191541.

3. Rambod M, Kovesdy CP, Kalantar-Zadeh K. Combined high serum ferritin and low iron saturation in hemodialysis patients: the role of inflammation. Clin J Am Soc Nephrol 2008;3(6):1691-1701. DOI: 10.2215/CJN.01070308.

4. Ashby DR, Gale DP, Busbridge M, et al. Plasma hepcidin levels are elevated but responsive to erythropoietin therapy in renal disease. Kidney Int 2009;75(9):976-981. DOI: 10.1038/ki.2009.21.

5. Babitt JL, Lin HY. Molecular mechanisms of hepcidin regulation: implications for the anemia of CKD. Am J Kidney Dis 2010;55(4): 726-741. DOI: 10.1053/j.ajkd.2009.12.030.

6. World Health Organization technical report series No. 405: nutritional anemias - report of a WHO Scientific Group. Geneva: WHO; 1968.

7. US Renal Data System. Annual Data Report: Atlas of End-Stage Renal Disease in the United States. Bethesda, MD: National Institutes of Health, National Institute of Diabetes and Digestive and Kidney Diseases; 2008.

8. Global Burden of Disease 2016 Disease and Injury Incidence and Prevalence Collaborators. Global, regional, and national incidence, prevalence, and years lived with disability for 328 diseases and injuries for 195 countries, 1990-2016: a systematic analysis for the Global Burden of Disease Study 2016. Lancet 2017;390(10100): 1211-1259. DOI: 10.1016/S0140-6736(17)32154-2.

9. Levey AS, de Jong PE, Coresh J, et al. The definition, classification, and prognosis of chronic kidney disease: a KDIGO Controversies Conference report. Kidney Int 2011;80(1):17-28. DOI: 10.1038/ ki.2010.483.

10. Khan SS, Kazmi WH, Abichandani R, et al. Health care utilization among patients with chronic kidney disease. Kidney Int 2002;62(1):229-236. DOI: 10.1046/j.1523-1755.2002.00432.x.

11. NIH: Department of Health and Human Services. (2014). Anemia in Chronic Kidney Disease. [online]. Available from http://www.pkdiet. com/pdf/anemia_508.pdf. [Last accessed December, 2019].

12. Atkinson MA, Warady BA. Anemia in chronic kidney disease. Pediatr Nephrol 2018;33(2):227-238. DOI: 10.1007/s00467-017-3663-y.

13. Warner MJ, Kamran MT. Anemia, Iron Deficiency. Treasure Island (FL): StatPearls Publishing; 2019.

14. Abbaspour N, Hurrell R, Kelishadi R. Review on iron and its importance for human health. J Res Med Sci 2014;19(2):164-174.

15. Nicolas G, Bennoun M, Devauxl, et al. Lack of hepcidin gene expression and severe tissue iron overload in upstream stimulatory factor 2 (USF2) knockout mice. Proc Natl Acad Sci USA 2001;98(15):8780-8785. DOI: $10.1073 /$ pnas.151179498.

16. Nemeth E, Tuttle MS, Powelson J, et al. Hepcidin regulates cellular iron efflux by binding to ferroportin and inducing its internalization. Science 2004;306(5704):2090-2093. DOI: 10.1126/science.1104742.

17. Mazur A, Feillet-Coudray C, Romier B, et al. Dietary iron regulates hepatic hepcidin 1 and 2 mRNAs in mice. Metabolism 2003;52(10):1229-1231. DOI: 10.1016/S0026-0495(03)00277-4.

18. Shah YM, Xie L. Hypoxia-inducible factors link iron homeostasis and erythropoiesis. Gastroenterology 2014;146(3):630-642. DOI: 10.1053/j.gastro.2013.12.031.

19. Silvestri L, Pagani A, Camaschella C. Furin-mediated release of soluble hemojuvelin: a new link between hypoxia and iron homeostasis. Blood 2008;111(2):924-931. DOI: 10.1182/blood-2007-07-100677.

20. Nemeth $E$, Valore EV, Territo $M$, et al. Hepcidin, a putative mediator of anemia of inflammation, is a type II acute-phase protein. Blood 2003;101(7):2461-2463. DOI: 10.1182/blood-2002-10-3235. 
21. Nicolas $G$, Chauvet $C$, Viatte $L$, et al. The gene encoding the iron regulatory peptide hepcidin is regulated by anemia, hypoxia, and inflammation. J Clin Invest 2002;110(7):1037-1044. DOI: 10.1172/ JCl0215686.

22. Zaritsky J, Young B, Wang HJ, et al. Hepcidin-a potential novel biomarker for iron status in chronic kidney disease. Clin J Am Soc Nephrol 2009;4(6):1051-1056. DOI: 10.2215/CJN.05931108.

23. Kato A, Tsuji T, Luo J, et al. Association of prohepcidin and hepcidin- 25 with erythropoietin response and ferritin in hemodialysis patients. Am J Nephrol 2008;28(1):115-121. DOI: 10.1159/000109968.

24. van der Weerd NC, Grooteman MP, Bots ML, et al. Hepcidin-25 in chronic hemodialysis patients is related to residual kidney function and not to treatment with erythropoiesis stimulating agents. PLoS One 2012;7(7):e39783. DOI: 10.1371/journal.pone.0039783.

25. Babitt JL, Lin HY. Mechanisms of anemia in CKD. J Am Soc Nephrol 2012;23(10):1631-1634. DOI: 10.1681/ASN.2011111078.

26. Besarab A, Ayyoub F. Anemia in renal disease. In: Schrier RW, ed. Diseases of the Kidney and Urinary Tract. Philadelphia: Lippincott Williams and Wilkins; 2007. pp. 2406-2430.

27. Keith DS, Nichols GA, Gullion CM, et al. Longitudinal follow-up and outcomes among a population with chronic kidney disease in a large managed care organization. Arch Intern Med 2004;164(6):659-663. DOI: 10.1001/archinte.164.6.659.

28. Kovesdy CP, Trivedi BK, Kalantar-Zadeh K, et al. Association of anemia with outcomes in men with moderate and severe chronic kidney disease. Kidney Int 2006;69(3):560-564. DOI: 10.1038/sj.ki.5000105.

29. Regidor DL, Kopple JD, Kovesdy CP, et al. Associations between changes in hemoglobin and administered erythropoiesis-stimulating agent and survival in hemodialysis patients. J Am Soc Nephrol 2006;17(4):1181-1191. DOI: 10.1681/ASN.2005090997.

30. Singh N, Agarwal AK. Pumping iron: revisiting risks, benefits and strategies in treatment of iron deficiency in end-stage renal disease. Clin Nephrol 2012;77(3):188-194. DOI: 10.5414/CN107266.

31. Thorp ML, Johnson ES, Yang X, et al. Effect of anaemia on mortality, cardiovascular hospitalizations and end-stage renal disease among patients with chronic kidney disease. Nephrology 2009;14(2): 240-246. DOI: 10.1111/j.1440-1797.2008.01065.x.

32. Finkelstein FO, Story K, Firanek C, et al. Health-related quality of life and hemoglobin levels in chronic kidney disease patients. Clin J Am Soc Nephrol 2009;4(1):33-38. DOI: 10.2215/CJN.00630208.

33. Irwin C, Moriarity-Suggs C. Anemia management in chronic and endstage kidney disease. US Pharma 2010;35(3)(Oncology/Hematology suppl):8-13.

34. Pasricha SR. Is it time for hepcidin to join the diagnostic toolkit for iron deficiency? Expert Rev Hematol 2012;5:153-155. DOI: 10.1586/ ehm.12.2.

35. Locatelli F, Bárány P, Covic A, et al. Kidney Disease: Improving global outcomes guidelines on anaemia management in chronic kidney disease: a European Renal Best Practice position statement. Nephrol Dial Transplant 2013;28(6):1346-1359. DOI: 10.1093/ndt/gft033.

36. Cappellini MD, Comin-Colet J, de Francisco A, et al. Iron deficiency across chronic inflammatory conditions: international expert opinion on definition, diagnosis, and management. Am J Hematol 2017;92(10):1068-1078. DOI: 10.1002/ajh.24820.

37. Ratcliffe LE, Thomas W, Glen J, et al. Diagnosis and management of iron deficiency in CKD: a summary of the NICE guideline recommendations and their rationale. Am J Kidney Dis 2016;67(4):548-558. DOI: 10.1053/j.ajkd.2015.11.012.

38. Kidney Disease: Improving Global Outcomes (KDIGO) Anemia Work Group. KDIGO clinical practice guideline for anemia in chronic kidney disease. Kidney Int Suppl 2012;2(1):279-335.

39. Tolkien Z, Stecher L, Mander AP, et al. Ferrous sulfate supplementation causes significant gastrointestinal side-effects in adults: a systematic review and meta-analysis. PLoS One 2015;10(2):e0117383. DOI: 10.1371/journal.pone.0117383.

40. KDOQI. KDOQI clinical practice guideline and clinical practice recommendations for anemia in chronic kidney disease: 2007 update of hemoglobin target. Am J Kidney Dis 2007;50(3):471-530. DOI: 10.1053/j.ajkd.2007.06.008.

41. Kliger AS, Foley RN, Goldfarb DS, et al. KDOQI US commentary on the 2012 KDIGO Clinical Practice Guideline for Anemia in CKD. Am J Kidney Dis 2013;62(5):849-859. DOI: 10.1053/j.ajkd.2013.06.008.

42. Rozen-Zvi B, Gafter-Gvili A, Paul M, et al. Intravenous versus oral iron supplementation for the treatment of anemia in CKD: systematic review and meta-analysis. Am J Kidney Dis 2008;52(5):897-906. DOI: 10.1053/j.ajkd.2008.05.033.

43. Avni T, Bieber A, Grossman A, et al. The safety of intravenous iron preparations: systematic review and meta-analysis. Mayo Clin Proc 2015;90(1):12-23. DOI: 10.1016/j.mayocp.2014.10.007.

44. Shepshelovich D, Rozen-Zvi B, Avni T, et al. Intravenous Versus Oral Iron Supplementation for the Treatment of Anemia in CKD: An Updated Systematic Review and Meta-analysis. Am J Kidney Dis 2016;68(5):677-690. DOI: 10.1053/j.ajkd.2016.04.018.

45. Sargent JA, Acchiardo SR. Iron requirements in hemodialysis. Blood Purif 2004;22(1):112-123. DOI: 10.1159/000074931.

46. Thavarajah S, Choi MJ. The Use of Erythropoiesis-Stimulating Agents in Patients with CKD and Cancer: A Clinical Approach. Am J Kidney Dis 2019;74(5):667-674. DOI: 10.1053/j.ajkd.2019.04.022.

47. Wish JB, Coyne DW. Use of erythropoiesis-stimulating agents in patients with anemia of chronic kidney disease: overcoming the pharmacological and pharmacoeconomic limitations of existing therapies. Mayo Clin Proc 2007;82(11):1371-1380. DOI: 10.4065/82.11.1371.

48. Hayat A, Haria D, Salifu MO. Erythropoietin stimulating agents in the management of anemia of chronic kidney disease. Patient Prefer Adherence 2008;2:195-200.

49. Aapro M, Osterwalder B, Scherhag A, et al. Epoetin- $\beta$ treatment in patients with cancer chemotherapy-induced anaemia: the impact of initial haemoglobin and target haemoglobin levels on survival, tumor progression and thromboembolic events. Br J Cancer 2009;101(12):1961-1971. DOI: 10.1038/sj.bjc.6605255.

50. Schaefer RM, Schaefer L. Iron monitoring and supplementation: how do we achieve the best results? Nephrol Dial Transplant 1998;13(90002 Suppl 2):9-12. DOI: 10.1093/ndt/13.suppl_2.9.

51. Coyne DW, Kapoian T, Suki W, et al. Ferric gluconate is highly efficacious in anemic hemodialysis patients with high serum ferritin and low transferrin saturation: results of the dialysis patients' response to IV iron with elevated ferritin (DRIVE) study. J Am Soc Nephrol 2007;18(3):975-984. DOI: 10.1681/ASN.2006091034.

52. Macdougall IC, White C, Anker SD, et al. Intravenous iron in patients undergoing maintenance hemodialysis. N Engl J Med 2019;380: 447-458. DOI: 10.1056/NEJMoa1810742. 